\title{
AVALIAÇÃO DE DESEMPENHO: UMA ANÁLISE EM CASO DE PROCESSO DE RECUPERAÇÃO JUDICIAL
}

\author{
Luana Santos Mateo ${ }^{1}$, Fabio Ibanhez Bertuchi ${ }^{1,2}$ \\ ${ }^{1}$ Centro Universitário Antônio Eufrásio de Toledo - TOLEDO, Curso de Ciências Contábeis, Presidente Prudente, SP. \\ ${ }^{2}$ Universidade Estadual de Maringá - UEM, Mestrado em Ciências Contábeis, Maringá, PR E-mail: \\ luanasantosmateo@hotmail.com, fabiobertuchi@hotmail.com
}

\section{RESUMO}

Em tempos de crise econômica, é necessário que as empresas criem mecanismos de controle e avaliação que auxiliem no gerenciamento pessoal e das atividades organizacionais objetivando superar a crise. 0 objetivo deste estudo consiste em comparar dois métodos de avaliação de desempenho de empresas que entraram com pedido de recuperação judicial na região Oeste Paulista do estado de São Paulo. A metodologia constou de bibliografias, artigos relacionados ao tema e processos que tramitam nas comarcas da cidade de Presidente Prudente e região. Os resultados foram que em análise ao plano de recuperação judicial da empresa objeto de análise, dentre os meios previstos no art. 50 da lei, foram contemplados apenas dois itens, dos dez instrumentos a serem aplicados. Concluímos que não há implantação de modelos de avaliação de desempenho nas empresas em situação de crise que buscaram respaldo no judiciário, limitando-se apenas as ações e práticas simples contempladas na lei.

Palavras-chave: Avaliação de Desempenho; BSC; ISO 9001; Competitividade; Recuperação Judicial.

\section{PERFORMANCE EVALUATION: AN ANALYSIS IN CASE OF JUDICIAL RECOVERY PROCESS}

\begin{abstract}
In times of economic crisis, it is necessary for companies to create control and evaluation mechanisms that assist in the management of personnel and organizational organizations in order to overcome the crisis. The state of shock in performance evaluation processes has entered judicial decline in the western region of São Paulo state. The methodology consists of bibliographies, articles related to the theme and processes that compose the districts of the city of Presidente Prudente and region. The results were analyzed in the judicial recovery plan of the company under analysis, among the means provided in art. 50 of the law, only two items were contemplated, of the ten instruments to be applied. It is concluded that there is no installation of performance evaluation models in companies in which the crisis situation cannot be considered judicial, limiting itself to simple actions and practices contemplated in the law.
\end{abstract}

Keywords: Performance evaluation; BSC; ISO 9001; Competitiveness; Judicial recovery.

\section{INTRODUÇÃO}

A globalização na economia, há tempos, vem estimulando a competitividade entre as empresas como principal forma de sobrevivência no mercado. Sendo assim, a exigência se volta para a adoção de técnicas modernas de administração, por meio de programas de excelência gerencial, aliados à mensuração dos resultados obtidos através dos colaboradores da empresa.

A avaliação de desempenho se sobressai por ser um método gerencial que permite ao avaliador utilizar essa ferramenta organizacional a qual foi desenvolvida por meio de um processo dinâmico que utiliza as informações sobre a entidade e sua performance empresarial, propondo soluções e melhorias a fim de que possam tornar as empresas mais competitivas no mercado.

Paladini (1995, p. 13) nos ensina que "não há forma de definir qualidade sem atentar para o atendimento integral ao cliente", contudo o autor salienta que "não há forma de atender ao cliente sem qualidade no processo produtivo". A partir dessa reflexão, podemos dizer que o resultado almejado depende do 
comprometimento de todos os envolvidos no processo produtivo. Para Dutra (2010, p. 14), quanto mais as organizações buscam flexibilidade mais dependem das pessoas; em decorrência, tornam-se mais dispostas a atender às expectativas e às necessidades que elas manifestam. Assim, as pessoas sempre procuram satisfazer a um novo conjunto de necessidades pessoais e profissionais e acabam pressionando as organizações a se estruturarem para tanto.

$\mathrm{O}$ presente estudo tem como objetivo geral buscar entendimento teórico acerca da avaliação de desempenho como um meio de apoio utilizado pelas organizações, comparando os métodos BSC com o ISO 9001, tendo vistas as empresas que entram com pedido de Recuperação Judicial. Ademais, buscou-se compreender se estas se utilizam de algum método de controle de qualidade para atingir o plano de recuperação judicial proposto.

\section{METODOLOGIA}

Trata-se de pesquisa bibliográfica que busca conceituar a avaliação de desempenho e os métodos BSC e ISSO 9001 buscando, nessas ferramentas, soluções para as empresas que entram com pedido de recuperação judicial. Quanto ao delineamento da pesquisa, trata-se de estudo de natureza descritiva quanto aos objetivos, bibliográfica quanto aos procedimentos e quantitativa quanto à abordagem do problema. Neste estudo, procurou-se identificar junto a uma empresa que entrou com pedido de recuperação judicial se esta contemplou algum modelo de avaliação de desempenho.

\section{RESULTADOS}

O universo de processos de recuperação judicial no Oeste Paulista é de 26 (vinte e seis) processos judiciais, dentro do contexto das comarcas, sendo que desses, 01 (um) foi utilizado como caso de estudo, em trâmite perante a Terceira Vara Cível da Comarca de Presidente Prudente - SP (São Paulo, 2016), consoante a Lei no 11.101/2005 em atendimento aos artigos 45, 47, 48 e 53. A empresa analisada foi denominada como EMP1, uma vez que isso poderia expor a mesma e interferir no processo de recuperação e superação da crise ao qual está enfrentando atualmente.

Já em relação ao Plano de Recuperação apresentado pela recuperanda EMP1 este propõe a concessão de prazos e as condições especiais para pagamento das obrigações vencidas e vincendas sujeitas aos efeitos da presente Recuperação Judicial, também limitado ao art. 50 da lei, onde buscou-se demonstrar a viabilidade econômico-financeira de recuperação da empresa, bem como a adequação entre a proposta de pagamento apresentada aos credores e a geração de caixa da entidade para cumprimento das obrigações ajustadas. Em contrapartida, cada credor tem por direito apresentar objeção ao plano de recuperação judicial apresentado.

Nesse contexto, em análise ao plano de recuperação judicial da empresa objeto de análise, verificou-se que dentre os meios previstos no art. 50 da lei, que possibilitam buscar superar a crise econômica e financeira, foram contemplados apenas dois itens, contudo, a legislação de forma especifica para empresas do porte e segmento dessa, poderiam contemplar ao menos dez instrumentos a serem aplicados pela recuperanda, limitando-se conforme demonstrado no quadro 1 a seguir: 
Quadro 1. Meios previstos no art. 50 comtemplado pela EMP1

\begin{tabular}{|c|c|}
\hline \multicolumn{1}{|c|}{ TÍTULO } & EMP1 \\
\hline (I) concessão de prazos e descontos para pagamento & Aplica-se \\
\hline (II) alteração do controle societário & $\mathrm{N}$ \\
\hline (II) aumento de capital social & $\mathrm{N}$ \\
\hline $\begin{array}{c}\text { (IV) trespasse ou arrendamento de estabelecimento, inclusive } \\
\text { à sociedade constituída pelos próprios empregados }\end{array}$ & $\mathrm{N}$ \\
\hline $\begin{array}{c}\text { (V) redução salarial, compensação de horários e redução da } \\
\text { jornada, mediante acordo ou convenção coletiva }\end{array}$ & $\mathrm{N}$ \\
\hline $\begin{array}{c}\text { (VI) dação em pagamento ou novação de dívidas do passivo, } \\
\text { com ou sem constituição de garantia própria ou de terceiro }\end{array}$ & $\mathrm{N}$ \\
\hline (VII) venda parcial dos bens & $\mathrm{N}$ \\
\hline (VIII) usufruto da empresa & $\mathrm{N}$ \\
\hline $\begin{array}{c}\text { (X) constituição de sociedade de propósito específico para } \\
\text { adjudicar, em pagamento dos créditos, os ativos do devedor }\end{array}$ & $\mathrm{N}$ \\
\hline
\end{tabular}

Fonte: Elaborado pelos autores.

Pelo que se extrai do plano de recuperação judicial da empresa varejista objeto de análise - além de outros fatores, podese atribuir dificuldades econômicas encontradas nos últimos anos, com uma grave crise financeira que chegou ao país, alavancando os preços dos insumos e gerando, portanto, uma grande queda na demanda. O setor varejista sentiu os principais impactos gerados pelas atuais crises econômica e política que o país enfrenta, com a alta dos custos e despesas não refletidas nos preços de vendas, associadas à queda das vendas em razão da economia que vem sendo realizada pelas famílias diante do cenário (SÃO PAULO, 2016).

Assim, com o passivo aumentado e com os resultados operacionais cada vez mais enxutos, devido ao aumento do custo dos insumos e à queda da demanda, a empresa enfrentou dificuldades no carregamento de seu endividamento, com baixa liquidez e até colocou em risco a continuação de suas atividades (SÃO PAULO, 2016).

Após o pedido de recuperação judicial, a recuperanda, por meio de seus administradores e com a equipe de consultores, desenvolveu um plano de reestruturação a ser aplicado em curto, médio e longo prazos, buscando contemplar mudanças em todos os setores da organização. Para tanto, apresentam-se propostas de redução de custos e despesas para comercialização e prestação do serviço, por meio de melhorias nas áreas comercial, administrativa e financeira. Além disso, nesta última, há procura incessante de redução dos custos financeiros, com a adequação do fluxo de caixa da operação (SÃO PAULO, 2016).

\section{AVALIAÇÃO DE DESEMPENHO}

A avaliação de desempenho é um poderoso instrumento de gestão e contribui com as organizações que pretendem obter sucesso nos dias atuais. Para tanto, é crucial medir o desempenho como um todo para obter benefícios nas práticas organizacionais.

"A avaliação de desempenho (AD) é um instrumento gerencial que permite ao administrador mensurar os resultados obtidos por um empregado ou por um grupo, em período e área específicos (conhecimentos, metas, habilidades etc.) ". (MARRAS, 2000, p. 173), assim, dentro da nova ordem gerencial, os sistemas precisam ser continuamente aperfeiçoados com a adoção de metodologias de 
avaliação modernas e o uso de novas ferramentas.

Contudo Chiavenato (2005, p. 8) afirma que: as pessoas devem ser visualizadas como parceiras das organizações. Como tais, elas são fornecedoras de conhecimentos, habilidades, competências, e, sobretudo, o mais importante aporte para as organizações: a inteligência que proporciona decisões racionais e que imprime significado e rumo aos objetivos globais. Neste sentido, as pessoas constituem parte integrante do capital intelectual da organização.

Araújo (2006, p.152) destaca as vantagens proporcionadas pelo processo de avaliação de desempenho, como sendo: situar as pessoas na estrutura organizacional; possibilitar a descoberta de novos talentos; auxiliar no aprimoramento da qualidade de vida; facilitar o feedback às pessoas da organização; incentivar a utilização de coaching; auxiliar o direcionamento de esforços da organização.

É difícil determinar, de forma genérica, quais os tipos de Avaliação de Desempenho são mais indicados para cada empresa. Essa é uma decisão que vai depender da política de pessoal e das características dos cargos envolvidos.

\section{BALANCED SCORECARD - BSC}

O Balanced Scorecard (BSC) é também considerado um método moderno utilizado para avaliar o desempenho dos colaboradores, tendo como função complementar a de monitorar o andamento e efetivar os objetivos anteriormente traçados.

A principal finalidade desse método é apontar as iniciativas que devem ser tomadas para se obter maiores resultados para organização e acompanhar os resultados decorrentes dessas ações para: alinhar as atividades de negócios para a visão estratégia da organização; melhorar as comunicações interna e externa; monitorar o desempenho organização em relação aos seus objetivos estratégicos.

Com o passar dos anos, foram criadas algumas ferramentas de mensuração e avaliação da estratégia que, segundo Rezende (2003, p. 11), são utilizadas para determinar a compatibilidade entre os objetivos $e$ as restrições, os níveis de turbulência ambiental e recursos disponíveis; para quantificar os hiatos existentes entre disponibilidade atual de competências e aquelas que uma organização deveria possuir; para embasar o desenvolvimento de competências; para estabelecer prioridades para constantes e permanentes revisões da trajetória em curso.

Segundo Chiavenato (2008, p. 274), Balanced Scorecard é uma ferramenta criada inicialmente por Kaplan e Norton (1997, p. 20) como um sistema de avaliação do desempenho empresarial. Seus criadores notaram que os métodos de avaliação adotados eram apenas indicadores financeiros que, por sua vez, não dão um resultado que se espera, pois medem os resultados dos investimentos e das atividades que geram renda para a empresa.

Para Kaplan e Norton (1997, p. 20), o Balanced Scorecard é mais do que um novo sistema de indicadores. Empresas estão utilizando-o na base de suas estruturas organizacionais e em seus processos gerenciais. "O verdadeiro poder do Balanced Scorecard, todavia, ocorre quando deixa de ser um sistema de medidas e se transforma em um sistema de gestão estratégica".

Algumas empresas que utilizam os pressupostos do BSC procuram decompor objetivos e metas organizacionais em medidas específicas no nível operacional (equipes de trabalho e indivíduos), visando alinhar iniciativas individuais, departamentais e organizacionais. Para gerenciar o desempenho individual, certas organizações utilizam ainda instrumentos que permitem mensurar a expressão de competências humanas no trabalho, sob a ótica de múltiplas fontes de avaliação (superior, colegas, subordinados e outros).

\section{ISO 9001}

Gestão de qualidade está relacionada as questões voltadas para custos, confiabilidade, procedimentos e a busca por estancar defeitos, nesse contexto, a ISO se mostra um modelo que preza por integrar em sua organização garantias de qualidade externa e interna.

Para Oliveira et al. (2011, p. 57) a economia há anos se globalizou, e desta forma acirrou a competitividade tornando seu ambiente altamente turbulento, desta forma, a continua busca da eficácia fez emergir nas empresas a preocupação cada vez maior com a qualidade de seus produtos em relação ao mercado consumidor, assim sendo as normas ISO 9000 tem sido objeto das atenções dos gestores.

Paladini et al. (2012, p. 161) destaca que a série ISO 9000 é composta por quatro normas principais, para atender a pesquisa em questão vamos nos utilizar da ISO 9001 a qual abrange 
sistemas de gestão de qualidade - requisitos. É importante ressaltar que esta norma contém requisitos a serem utilizados para atender eficazmente os requisitos de clientes e regulamentares aplicáveis e para aumentar a satisfação do cliente.

Por meio da ISO, uma organização melhora a prestação de serviço ao cliente, além disso, também é usada para medir o nível de satisfação dos clientes, melhorando a eficácia da gestão da empresa. Marshall Junior (2010, p. 68) destaca que a normalização se resume em uma atividade que estabelece prescrições destinadas a utilização comum e repetitiva.

\section{A RECUPERAÇÃO JUDICIAL}

Em 09 de fevereiro de 2005, foi sancionada a Lei 11.101 - lei de falência e recuperação de empresas - que prevê novas disposições para os casos de falência e recuperação judicial e extrajudicial para as empresas. Neste contexto, a solução da empresa em crise passou do antigo regime da concordata - o qual concedia um tipo de "favor" para fins de dilação de prazo de suas obrigações ou até redução parcial do débito na oportunidade, evitando, dessa forma, a falência - para o modelo atual existente na legislação em vigência, que trata da recuperação judicial.

Refere-se de um instrumento à disposição da empresa em situação econômica agravada, tendo como proposito contribuir com sua reestruturação da mesma. Nesse contexto, traz como conteúdo estratégias diversas que possuem o objetivo de afastar a crise presente na empresa em recuperação, buscando promover a preservação da empresa, sua função social e o estímulo à atividade econômica.

A recuperação judicial não visou tão somente a preservação da empresa, afastando uma futura falência, mas também trouxe grande inovação em seu objetivo, buscando viabilizar a superação da situação de crise econômicofinanceira do devedor, além de permitir a manutenção da fonte produtora, do emprego dos trabalhadores e dos interesses dos credores, promovendo, assim, a preservação da empresa, sua função social e o estímulo à atividade econômica (art. 45, LRF).

$\mathrm{O}$ art. 48 da lei demonstra claramente que poderá requerer recuperação judicial 0 devedor que, no momento do pedido, exerça regularmente suas atividades há mais de 2 (dois) anos e que atenda aos requisitos estabelecidos.
A recuperação judicial pretende viabilizar a superação da situação de crise econômicofinanceira do devedor, a fim de permitir a manutenção da fonte produtora, do emprego dos trabalhadores e dos interesses dos credores, promovendo, assim, a preservação da empresa, sua função social e o estímulo à atividade econômica. (Art. 47, LRF).

Nesse contexto, o plano de recuperação judicial é fundamental. Conforme apresenta Coelho (2016, p. 226-227), trata de instrumento fundamental no processo de recuperação judicial, uma vez que, sem o plano, se faz impossível atingir o propósito da lei 11.101/05, qual seja, a superação da crise financeira-econômica enfrentada pela recuperanda.

Importante destacar, à luz do art. 61 da LRE, que uma vez concedida, a devedora permanecerá em recuperação judicial, até que se cumpram integralmente as obrigações previstas no plano que se vencerem em até dois anos da concessão da recuperação judicial, no entanto, havendo descumprimento das obrigações assumidas no plano de recuperação judicial, acarretará a convolação da recuperação judicial em falência (art. 73, inciso IV).

\section{CONSIDERAÇÕES FINAIS}

Neste trabalho, mostrou-se que os benefícios obtidos em uma avaliação de desempenho são enormes, pois, por meio dela, é possível medir o grau de contribuição de cada colaborador, dos procedimentos e obter medidas de controle para tomada de decisão.

Além de outros fatores, pode-se atribuir o início das dificuldades da recuperanda às turbulências econômicas enfrentadas por todo o país nos últimos anos, em razão de uma grave crise financeira, alavancando os preços dos insumos e gerando, dessa forma, uma grande queda na demanda. Entretanto, verificou-se que a mesma não contemplava nenhum tipo de mensuração de desempenho.

Ao analisar o plano de recuperação judicial apresentado ao processo, o qual foi elaborado por uma empresa de consultoria, é possível observar o esforço que a empresa recuperanda deverá ter para obter resultados positivos junto às negociações assumidas.

A principal finalidade do BSC é apontar as iniciativas que devem ser tomadas para se obter maiores resultados para organização e acompanhar os resultados decorrentes dessas ações para: alinhar as atividades de negócios para 
a visão estratégia da organização; melhorar as comunicações interna e externa; monitorar o desempenho e organização em relação aos seus objetivos estratégicos.

Neste mesmo sentido, a empresa pode optar por implantar a ISO 9001, que ajudaria com melhores resultados no que tange à prestação de serviço ao cliente. Ademais, tal ferramenta auxilia a medir o nível de satisfação dos clientes, melhorando a eficácia da gestão da empresa.

Observa-se que a empresa não delimitou a implantação de estratégias organizacionais como a utilização do Balanced Scorecard (BSC) ou a ISO 9001, bem como qualquer outro modelo de avaliação de desempenho que poderia ajudar na reestruturação e mensuração de resultados, assim como na elaboração de metas específicas para cada período.

Diversos outros estudos e análise podem ser realizados a partir deste. Há outros fatores a serem compreendidos que diretamente estão associados a avaliação de desempenho e as empresas em recuperação judicial, bem como entender suas escolhas. Da mesma forma, o tema recuperação judicial é relevante neste momento, face as dificuldades internas e externas encontradas pelas empresas e o número crescente de entidades que buscaram ao longo dos últimos anos esse mecanismo como forma de superar a crise.

\section{REFERÊNCIAS}

ARAÚJO, L. C. G. de. Gestão de Pessoas: Estratégias e integração organizacional. São Paulo: Atlas, 2006.

CHIAVENATO, I. Teoria geral da administração. Rio de Janeiro: Campus, 2002.

CHIAVENATO, I. Gerenciamento com as pessoas: transformando o executivo em um excelente gestor de pessoas. 5. ed. Rio de Janeiro: Elsevier, 2005.

Recursos Humanos: o capital humano das organizações. 8.ed. São Paulo: Atlas, 2006.

CHIAVENATO, I. Os novos paradigmas, como as mudanças estão mexendo com as empresas. 5.ed. Rio de Janeiro: Manole, 2008.

COELHO, F. U. Comentários à Lei de Falência e Recuperação de Empresas. 12. ed. São Paulo: Revista dos Tribunais, 2016.
DUTRA, J. S. Competências: conceitos e instrumentos para a gestão de pessoas na empresa moderna. São Paulo: Atlas, 2010.

KAPLAN, R. S.; NORTON, D. P. Kaplan e Norton na prática. 7. Ed. Rio de Janeiro: Elsevier Publishing Company, 2004.

KAPLAN, R. S.; NORTON, D. P. A estratégia em ação: Balanced Scorecard. Rio de Janeiro: Campus, 1999.

MARSHALL JUNIOR, I. et al. Gestão da Qualidade. 10.ed. Rio de Janeiro: FGV, 2010.

MARRAS, J. P. Administração de Recursos Humanos. 3.ed. São Paulo: Futura, 2000.

OLIVEIRA, O. J. Gestão da qualidade: tópicos avançados. São Paulo: Cengage Learning, 2011.

PALADINI, E. P. Gestão da qualidade: teorias e casos. 22.ed. São Paulo: Elsevier, 2012.

PALADINI, E. P. et al. Gestão de qualidade no Processo: a qualidade na produção de bens e serviços. São Paulo: Atlas, 1995.

REZENDE, F. Balanced Scorecard e a Gestão do Capital Intelectual: alcançando a performance baseada na economia do conhecimento. Rio de Janeiro: Campus, 2003.

SÃO PAULO. Tribunal de Justiça de São Paulo. Terceira Vara Cível da Comarca de Presidente Prudente. Recuperação Judicial. Presidente Prudente, 2016.

Recebido para publicação em 25/05/2018

Revisado em 27/08/2018

Aceito em 06/09/2018 